\title{
INVESTIGATION OF FLOOD ROUTING USING VARIABLE PARAMETER KINEMATIC WAVE MODEL (VPKWM) FOR NON-PRISMATIC NATURAL CHANNEL IN AN UNGAUGED BASIN
}

\author{
B. Bharali ${ }^{\text {a }}$, U.K. Misra ${ }^{\text {a }}$ \\ ${ }^{a}$ Civil Engineering Department, Assam Engineering College, Jalukbari, Guwahati, Assam, India, \\ e-mails: * biswadeepbharali1989@gmail.com,utpal_misra2004@yahoo.com
}

Received: 12.05.2020 / Accepted: 06.06.2020/ Revised: 13.07.2020 / Available online: 15.12.020

DOI: 10.2478/jaes-2020-0017

KEY WORDS: SCS-CN, Flood Routing, Saint-Venant, Kinematic Wave Model, Ungauged Basin.

\begin{abstract}
:
This research concerns about the development and application of Variable Parameter Kinematic Wave Numerical model (VPKWM) based on 1-D Saint-Venant equation, to study the behaviour of the propagation of a flood wave in Non-prismatic natural waterways in an ungauged basin. The channel slope and wetted perimeter are considered as variable because of the irregularity of the boundary of the channel and the change in magnitude of discharge. The scarcity of reliable inflow data at upstream is a serious problem for the flood routing process in an ungauged basin. In this study the inflow hydrograph and lateral inflow hydrographs are obtained using SCS-CN method as rainfall runoff model. The performance of the model assessed considering four parameters such as root mean square error (RMSE), peak discharge, peak time and total volume. The results indicated that the VPKWM for non-prismatic channel provided reasonable output compared with the observed data.
\end{abstract}

\section{INTRODUCTION}

In order to ensure ample protection from flood and to obtain viable solution to it we required flood routing. Flood routing helps in designing proper hydraulic structure and flood protection measures for estimating how the proposed measure will affect the behaviour of flood waves. The outflow hydrograph at downstream location can be estimated by using a flood routing model by routing a flood event from an upstream gauging station, but in developing countries most of the basins are ungauged. The International Association of Hydrological Sciences (IASH) has recognized the need to shift the main focus of hydrology from gauged to ungauged catchments. This shift is intended to create a significant momentum among the hydrological community and to lead to the improvement of data acquisition and utilization, theories and models in the field of hydrology (Sivapalan et. al, 2003). The IAHS has launched a decadal initiative entitled Predictions in Ungauged Basins (PUB) in order to support this recognition.

Flood routing by distributed system methods is referred to as hydraulic routing. Distributed flood routing model can be used to describe the transformation of rainfall into run off over a basin to produce a flow hydrograph at the outlet of the basin. In this study hydraulic routing techniques is adopted to estimate the hydrograph at the downstream of the Kulsi River Basin.
Hydraulic routing model involves numerical solution of onedimensional Saint Venart Equation in open channel flow (French 1985). As noted by U.S Army Corps of Engineers (1994), while evaluating the best appropriate method for flood routing, various vital factors are to be considered, which include- backwater effects, flood plains, channel slope, hydrograph characteristics, flow network, subcritical and supercritical flow. However, there are also some vital factors which influence the routing model selection process which include the required accuracy, the type of data available and also its availability, the computational facilities available, its cost and the familiarity of the user with the given model (NERC, 1975; Fread, 1981)

The Kinematic wave routing method has the ability to transform the flood wave with the help of the system without attenuation of the peak flow (Nwaogazie 1986). The Kinematic wave routing model helps to calculate the resulting changes in flow, velocity and depth associated with the flow waves (Ambrose \& Wool 2017). To solve Kinematic wave hydraulic routing finite difference and finite element method are used. Chapra (1997) has described an explicit method to solve Kinematic wave routing method. However, a partially implicit method is narrated by Chow et. al. (1988) and a fully implicit method is used in USEPA's Water Quality Analysis Simulation Program (WASP) (Ambros \& Wool, 2017).

* Corresponding author: Biswadeep Bharali, Research Scholar, Civil Engineering Department, Assam Engineering College, Jalukbari, Guwahati, Assam, India, e-mail: biswadeepbharali1989@gmail.com. 
(Swamee.K.P. et.al, 2008). They tested Lacey's equations for the river Brahmaputra. They found that the river follows the structure of Lacey's regime equations. The perimeter and the area coefficients found in the modified regime equations are much higher than the corresponding coefficients in Lacey's original equations.

Similarly, the velocity coefficient for the river Brahmaputra is considerably smaller than the coefficient in Lacey's corresponding velocity equation, whereas the coefficients of the equations for the hydraulic radius are of the same order.

\section{STUDY AREA AND DATA BASE}

\subsection{Study Area}

The Kulsi River Basin, a part of the Brahmaputra sub-basin, was selected for this study and was considered hypothetically ungauged basin. The Kulsi River drains a total area of 2822.99 $\mathrm{km}^{2}$, covering the Kamrup District of Assam, the Western Khasi Hills, and the Ri Bhoi District of Meghalaya in Northeast India. The selected basin is an ideal target for flood routing due to its strategic location (encompassing two states in the northeast) and the fact that the region experiences large floods. The Kulsi River Basin is situated on the south bank of the mighty Brahmaputra River. It is located between latitude $25^{\circ} 30^{\prime} \mathrm{N}$ to $26^{\circ} 10^{\prime} \mathrm{N}$ and longitude $89^{\circ} 50^{\prime} \mathrm{E}$ to $91^{\circ} 50^{\prime} \mathrm{E}$ (Figure 1(a).). The area that the Kulsi River drains can be broadly divided into three reaches: (i) the Upper Khasi hill reach; (ii) the middle reserve forest reach; and (iii) the alluvial or flood plain reach.

\subsection{Data}

The daily field rainfall data for the year 2010 were collected from Indian Metrological Department (IMD), Guwahati. The daily discharge data at the outlet for 2010 were collected from National Institute of Hydrology, Guwahati. Digital elevation models (DEM) are being widely used for watershed delineation, extraction of stream networks and characterization of watershed topography (elevation map, slope map and aspect map) by using watershed delineation tool in ArcGIS software. DEM used in this project is collected from Carto Sat 1_V3_R1. CartoDEM version_3R1 is a national DEM developed by Indian Space Research Organization (ISRO). CartoDEM version_3R1 has resolution of $30.87 \times 30.87 \mathrm{~m}$ (or $1 \mathrm{Arc} \mathrm{Sec}$ ). For the delineation of the Kulsi River Watershed the Geotiff CartoDEMs are ng46g, ng46h, ng46m and ng46n.

The soil data for this project was obtained from the Harmonized World Soil Database v 1.2 of the Food and Agriculture Organization (FAO) soil portal. The soil data for the study area was downloaded from the Food and Agriculture Organization (FAO). The soil texture of the Kulsi River Watershed consists of clay loam, loam, sandy loamy (Figure 1(b)). The hydrological classification of soil for Kulsi River Watershed is shown in Figure 2.
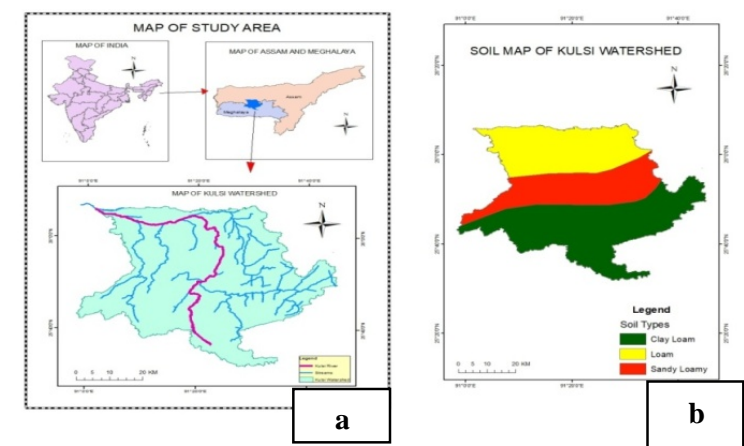

Figure 1. (a) Location of Kulsi River Watershed; (b) Map of soil texture of the Kulsi River Watershed

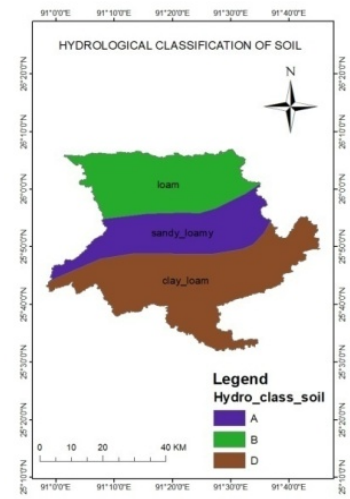

Figure 2. Map of Hydrological Classification

\subsection{Land Use and Land Cover (LULC)}

The LULC for the Kulsi River Watershed is done by performing Supervised Image Classification as per the required class sample Using ArcGIS 10.1 software. Linear Imaging Self Scanning Sensor (LISS)-III Satellite image is used in this project to perform Supervised Image Classification. The LISSIII image is downloaded from Bhuvan. The LULC map of the study area is shown in Figure 3.

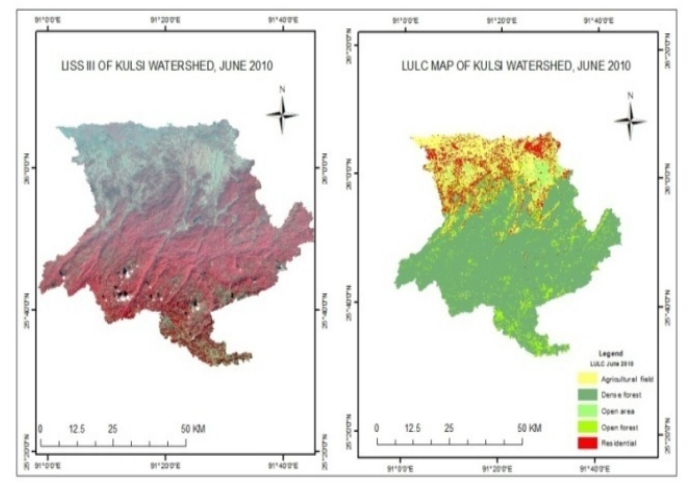

Figure 3. Map of LULC for Kulsi River Watershed of Soil for Kulsi River Watershed 


\subsection{Sub-basins of Kulsi Watershed}

Eight lateral inflows have been identified contributing to the main Kulsi River. Sub-basins for lateral inflows are delineated using ArcGIS 10.1. The details of the lateral flows and subbasins are presented in Figure 4 and 5.

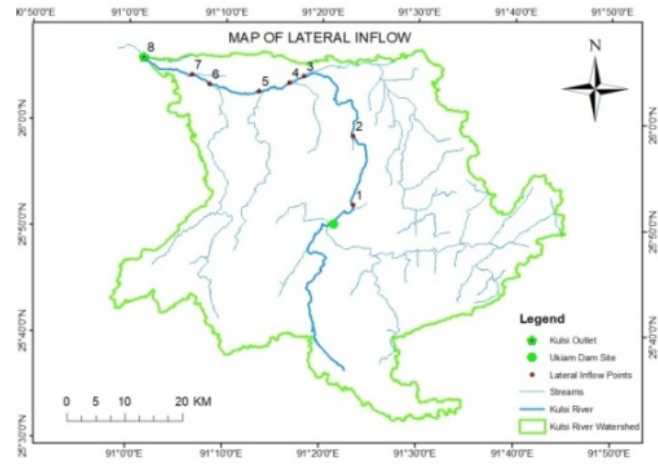

Figure 4. Lateral Inflows of Kulsi River Watershed

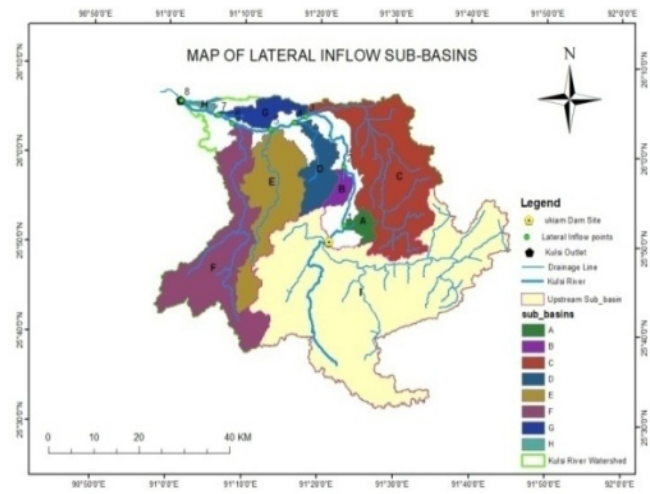

Figure 5. Details of Sub-Basins of Kulsi River Watershed

\subsection{Rainfall Data Distribution}

The rainfall distributed is performed over the study area by interpolation method using Arc GIS software. IDW, Kriging, and Spline are the three general methods available in Arc GIS 10.1 for interpolation. In this study Inverse Distance Weighted (IDW) method is used for rainfall interpolation as IDW is the best for the point data format.

The Filed rainfall data is collected from 7 numbers of rain gauge stations around Kulsi Watershed. It has been observed that in the year 2010 the month June experienced maximum amount of rainfall. For this study daily rainfall for the month of June, 2010 is distributed over the study area using IDW using ArcGIS 10.1. The minimum and maximum daily rainfall data for the month June is presented in Figure 6. The locations of the rain gauge stations are shown in Figure 7.

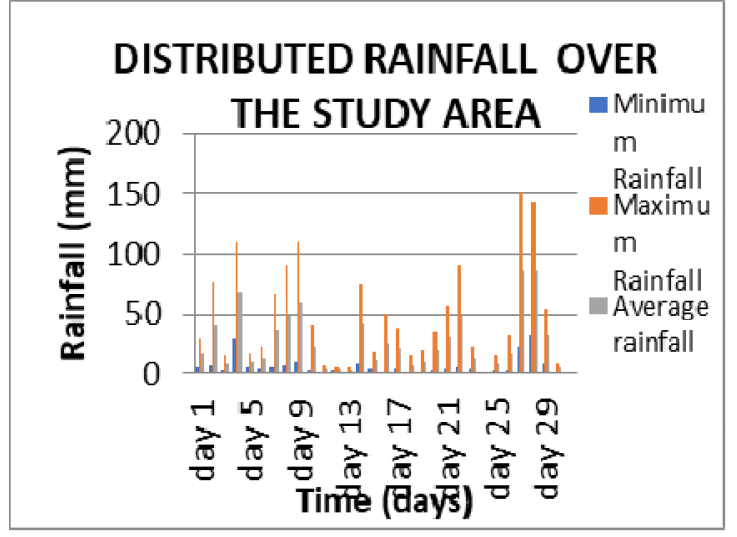

Figure 6. Distributed Rainfall Data over Kulsi River Watershed

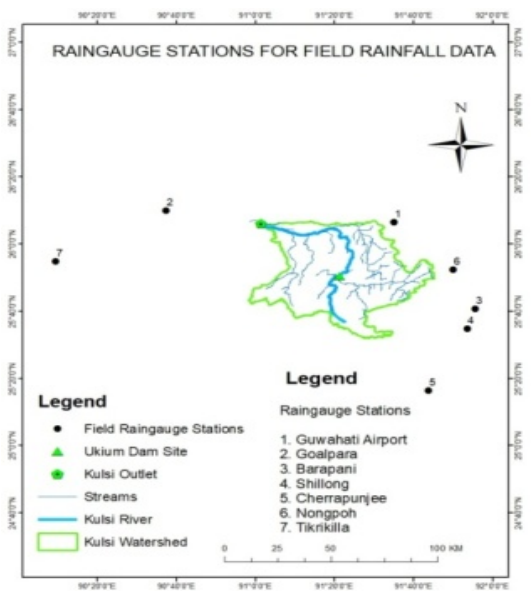

Figure 7. Map of Field Rain gauge stations around Kulsi River Watershed

\section{METHODOLOGY}

\subsection{SCS-CN Method}

In this study SCS-CN method is used as a Rainfall Runoff model to obtain inflow hydrograph at the upstream of the ungauged basin. SCS-CN method developed by Soil Conservation Services (SCS) of USA in 1969 is a simple, predictable and stable conceptual method for estimation of direct runoff depth based on storm rainfall depth. It relies on only one parameter, Curve Number $(\mathrm{CN})$. Currently, it is a wellestablished method, having been widely accepted for use in India and many other countries.

The SCS-CN method is based on the water balance equation and two fundamental hypotheses. The first hypothesis equates the ratio of the amount of direct surface runoff $Q$ to the total rainfall $\mathrm{P}$ (or maximum potential surface to the runoff) with the ratio of the amount of infiltration $F_{c}$ amount of the potential maximum retention $\mathrm{S}$. The second to the potential hypothesis relates the initial abstraction Ia maximum retention. [Subramanya K. (2008)]. 
(a) Water balance equation:

$$
\mathrm{P}=\mathrm{I}_{\mathrm{a}}+\mathrm{F}_{\mathrm{c}}+\mathrm{Q}
$$

Proportional equality hypothesis:

$$
\mathrm{Q} /\left(\mathrm{P}-\mathrm{I}_{\mathrm{a}}\right)=\mathrm{F}_{\mathrm{c}} / \mathrm{S}
$$

retention $(\mathrm{S})$

(b) $I_{a}$ is some fraction of the potential maximum

where: $\mathrm{P}$ is the total rainfall, Ia the initial abstraction, $\mathrm{F}_{\mathrm{c}}$ the cumulative infiltration excluding $I_{a}, Q$ the direct Surface runoff, $\mathrm{S}$ the potential maximum retention or infiltration and $\lambda$ the regional parameter dependent on geologic and climatic factors $(0.1<\lambda<0.3)$.

Solving Equation (2):

$Q=\frac{\left(P-l_{a}\right)^{2}}{P-l_{a}+S} \quad$ if $\mathrm{P}>\mathrm{I}_{\mathrm{a}}$, otherwise $\mathrm{Q}=0$

$\mathrm{Q}=(\mathrm{P}-\lambda \mathrm{S})^{2} /(P-(\lambda-1) \mathrm{S})$

The relation between Ia and $S$ was developed by analysing the rainfall and runoff data from experimental small watersheds and is expressed as $I_{a}=0.2 \mathrm{~S}$. Combining the water balance equation and proportional equality hypothesis, the SCS-CN method is represented as

$Q=\frac{(P-0.2 \mathrm{~S})^{2}}{P+0.8 \mathrm{~S}}$

The potential maximum retention storage $\mathrm{S}$ of watershed is related to a Curve Number $(\mathrm{CN})$, which is a function of land use, land treatments, soil type and antecedent moisture condition of watershed. The $\mathrm{CN}$ is dimensionless and its value varies from 0 to 100 .The $\mathrm{S}$-value in $\mathrm{mm}$ can be obtained from $\mathrm{CN}$ by using the relationship

$\mathrm{S}=25400 / C N-254$

3.1.1 Curve Number: In determining the $\mathrm{CN}$, the hydrological classification is adopted. Here soils are classified into four classes A, B, C and D based on the infiltration and other characteristics. The important soil characteristics that influence the hydrological classification of soils are effective depth of soil, average clay content, infiltration characteristics and the permeability. In this study the variation of curve number for various land conditions and for different hydrological classification is obtained from Applied Hydrology Book by Ven Te Chow, pp-150, 1988.

\subsection{Kinematic Wave Method}

Kinematic waves govern flow when inertial and pressure forces are not important. In a kinematic wave, the gravity and friction forces are balanced, so the flow does not accelerate appreciably

3.2.1 Kinematic Wave Celerity: A wave is a variation in a flow, such as a change in flow rate or water surface elevation, and the wave celerity is the velocity with which this variation travels along the channel. The celerity depends on the type of wave being considered and may be quite different from the water velocity. For a kinematic wave the acceleration and pressure terms in the momentum equation are negligible, so the wave motion is described principally by the equation of continuity. The name kinematic is thus applicable, as kinematics refers to the study of motion exclusive of the influence of mass and force.

The kinematic wave model is defined by the following equations.

Continuity Equation:

$\frac{\partial Q}{\partial x}+\frac{\partial A}{\partial t}=q$

Momentum Equation:

$\mathrm{S}_{0}=\mathrm{S}_{\mathrm{f}}$

The momentum equation can also be expressed in the form

$A=\alpha Q^{\beta}$

Manning's equation written with $S_{0}=S_{\mathrm{f}}$ and $R=A / P$ is:

$$
Q=\frac{S_{0}^{1 / 2}}{n P^{2 / 3}} A^{5 / 3}
$$

This can be solved for A as:

$A=\left(\frac{n P^{2 / 3}}{\sqrt{S_{0}}}\right)^{3 / 5} Q^{3 / 5}$

So, $\left.\alpha=\left[n P^{-\frac{2}{3}} / \sqrt{S_{0}}\right)\right]^{0.6}$ and $\beta=0.6$ for kinematic wave model.

Equation (8) contains two dependent variables, $A$ and $Q$, but $A$ can be eliminated by differentiating (10):

$\frac{\partial A}{\partial t}=\alpha \beta Q^{\beta-1}\left(\frac{\partial Q}{\partial t}\right)$

and substituting for $\frac{\partial A}{\partial t}$ in Equation (8) to give

$\frac{\partial Q}{\partial x}+\alpha \beta Q^{\beta-1}\left(\frac{\partial Q}{\partial t}\right)=q$

\subsection{Numerical Solution of Kinematic Wave Model:}

The solution of the Kinematic wave equations specifies the distribution of flow as a function of distance $\mathrm{x}$ along the channel and time $t$. The solution may be obtained numerically by using finite difference method or analytically by solving simultaneously the characteristics equations. According to chow (1988), the Saint-Venant equations for distributed routing are not amenable to analytical solution except in a few special simple cases. They are partial differential equations and must be solved using numerical methods. 
Methods for solving partial differential equations may be classified as direct numerical methods and characteristics methods. In direct methods, finite difference equations are formulated from the original partial differential equations for continuity and momentum. In characteristics methods, the partial differential equations are first transformed to a characteristics form and the characteristics equations are solved analytically by using a finite-difference representation. In numerical methods for solving partial difference equations, the calculations are performed on a grid placed over the $x$-t plane. The $\mathrm{x}$-t grid is a network of points defining by taking distance increments of length $\Delta \mathrm{x}$ and the time increments of duration $\triangle \mathrm{t}$. As in Kinematic Wave, celerity $\mathrm{c}=\frac{\partial Q}{\partial A}=\frac{\partial x}{\partial t}$ and the courant condition is $\mathrm{C} \frac{\partial t}{\partial x} \leq 1$. Kinematic wave model satisfies the courant condition and numerically stable.

In this study finite-difference method is used as a numerical solution for the kinematic wave model. A finite-difference method may employ either an explicit scheme or an implicit scheme for solution. Implicit scheme is used as the finitedifference method for kinematic wave model using MATLAB software and the flow chart of the proposed model is presented in figure 9.

As shown in Equation (14), the continuity and momentum equations for the kinematic wave can be combined to produce an equation with $Q$ as the only dependent variable. The objective of the numerical solution is to solve Equation (14) for $Q(x, t)$ at each point on the $x$ - $t$ grid, given the channel parameters $\alpha$ and $\beta$, the lateral inflow $q(t)$, and the initial and boundary conditions. To solve Equation (14) numerically, the time and space derivatives of $Q$ are approximated on the $x$ - $t$ grid as shown in Figure.8. The unknown value is $Q_{i+1}^{j+1}$.The values of $Q$ on the $j^{\text {th }}$ time line have been previously determined, and so has $Q_{i}^{j+1}$. $Q_{i+1}^{j+1}$ is computed as a linear function of the known values of $Q$.

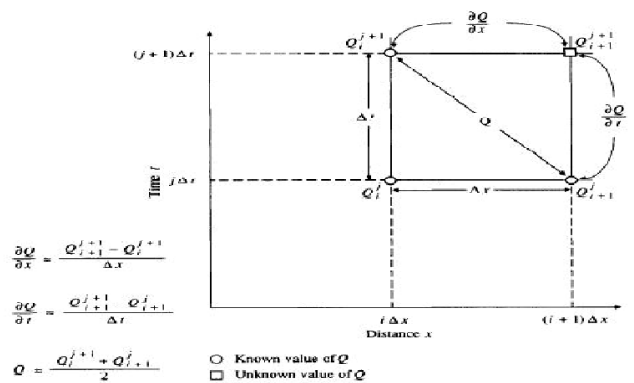

Figure 8. Finite difference box for solution of the linear kinematic wave equation showing the finite difference equations (Source: Applied hydrology by Ven Te chow, 1988)

\subsubsection{Linear Scheme of kinematic wave model:}

The backward-difference method is used to set up the finitedifference equations. The finite-difference form of the space derivative of $Q_{i+1}^{j+1}$ is found as (Figure 8.)

$\frac{\partial Q}{\partial x}=\frac{Q_{i+1}^{j+1}-Q_{i}^{j+1}}{\Delta x}$
The finite-difference form of the time derivative is found as (Figure 8.)

$\frac{\partial Q}{\partial t}=\frac{Q_{i+1}^{j+1}-Q_{i+1}^{j}}{\Delta t}$

If the value of $Q_{i+1}^{j+1}$ were used for $Q$ in the term $\alpha \beta Q^{\beta-1}$ in Equation (14) the resulting equation would be nonlinear in $Q_{i+1}^{j+1}$. To create a linear equation, the Value of $Q$ used in $\alpha \beta Q^{\beta-1}$ is found by averaging the values across the diagonal in the box shown in Figure 8:

$Q=\frac{Q_{i+1}^{j}+Q_{i}^{j+1}}{2}$

The value of lateral inflow $q$ is found by averaging the values on the $(i+1)^{\text {th }}$ distance line

$q=\frac{q_{i+1}^{j+1}+q_{i+1}^{j}}{2}$

Substituting in Equation (14), the finite-difference form of the linear kinematic wave is obtained:

$\frac{Q_{i+1}^{j+1}-Q_{i}^{j+1}}{\Delta x}+\alpha \beta\left(\frac{Q_{i+1}^{j}+Q_{i}^{j+1}}{2}\right)^{\beta-1}\left(\frac{Q_{i+1}^{j+1}-Q_{i+1}^{j}}{\Delta t}\right)=\frac{q_{i+1}^{j+1}+q_{i+1}^{j}}{2}$

This equation, solved for the unknown $Q_{i+1}^{j+1}, i s$

$Q_{i+1}^{j+1}=\frac{\left[\frac{\Delta t}{\Delta x} Q_{i}^{j+1}+\alpha \beta Q_{i+1}^{j}\left(\frac{Q_{i+1}^{j}+Q_{i}^{j+1}}{2}\right)^{\beta-1}+\Delta t\left(\frac{q_{i+1}^{j+1}+q_{i+1}^{j}}{2}\right)\right]}{\frac{\Delta t}{\Delta x}+\alpha \beta\left(\frac{Q_{i+1}^{j}+Q_{i}^{j+1}}{2}\right)^{\beta-1}}$

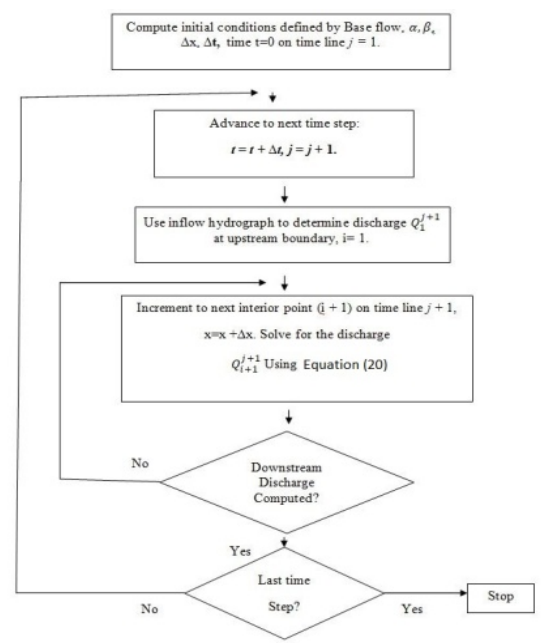

Figure 9. Flowchart for linear Kinematic Wave Model (KWM)

It has been observed that the flow parameters are not constant throughout the natural channel reach due to the irregular boundary and unsteady flow. The KWM is modified considering the channel is non-prismatic and the flow is unsteady. In Equation (20) the term ' $\alpha$ ' is dependent on wetted perimeter and slope of the channel. In non-prismatic unsteady flow natural channel, the wetted perimeter and slope is not constant throgyghout the channel reach. In this model the 
manning's roughness coefficient ' $n$ ' is considered to be constant throughout the channel reach. The equation for modified Variable Parameter Kinematic Wave Model (VPKWM) is given in Equation (21)

$$
Q_{i+1}^{j+1}=\frac{\left[\frac{\Delta t}{\Delta x} Q_{i}^{j+1}+\alpha(i, j) \beta Q_{i+1}^{j}\left(\frac{Q_{i+1}^{j}+Q_{i}^{j+1}}{2}\right)^{\beta-1}+\Delta t\left(\frac{q_{i+1}^{j+1}+q_{i+1}^{j}}{2}\right)\right]}{\frac{\Delta t}{\Delta x}+\alpha(i, j) \beta\left(\frac{Q_{i+1}^{j}+Q_{i}^{j+1}}{2}\right)^{\beta-1}}
$$

Where, $\left.\alpha(i, j)=\left[n(P(i, j))^{\frac{2}{3}} / \sqrt{S_{0}}\right)\right]^{0.6}$ and $\beta=0.6$

\section{OBSERVATION AND ANALYSIS}

\subsection{SCS-CN Rainfall-Runoff Model in Kulsi River Watershed}

Flow routing is a procedure to determine the time and magnitude of flow (i.e the outflow hydrograph) at a point on a watercourse from the known inflow hydrograph at upstream gauged station. If the flow is flood the procedure is considered as flood routing. But in case of ungauged basin inflow hydrograph is not available for flood routing. So, SSC-CN rainfall-runoff model is used for the prediction of inflow hydrograph at the upstream end (@ Ukiam Dam Site) of the Kulsi River Watershed. SSC-CN model is used to determine the direct surface runoff hydrograph for each lateral inflow. The runoff discharge for each sub-basin is presented in Figure 10.

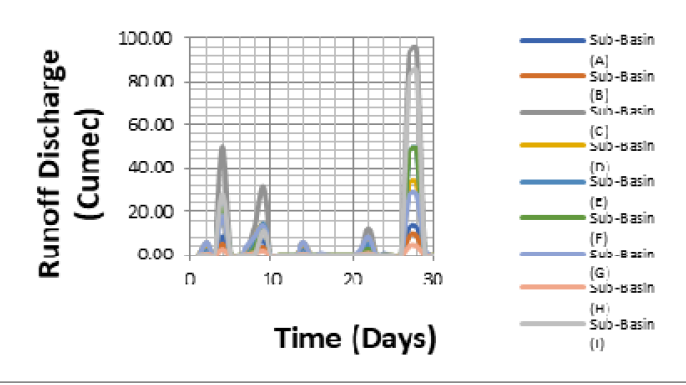

Figure 10. Estimation of runoff discharge of each sub-basin using SSC-CN method by using Field Rainfall Data (FRD)

\subsection{Kinematic wave model (KWM) for Kulsi River} Watershed considering as prismatic channel

In hydraulic routing model the rate of flow to be computed as function of space and time. The numerical solution for Kinematic Wave Model (KWM) for prismatic channel is coded in MATLAB software. Equation (20) is used to solve this model. The total length of the channel reach from upstream (Ukiam Dam site) to downstream (Kulsi outlet) is divided into sections of $15 \mathrm{KM}$ and the time interval is one day. The term ' $\alpha$ ' of Equation (20) is:

$\left.\alpha=\left[n P^{\frac{2}{3}} / \sqrt{S_{0}}\right)\right]^{0.6}$

The wetted perimeter with discharge for natural rivers follows Lacey (for stable River Channel) presented in Equation. (23). (1930; 1947, cited by Punmia and Pande, 1981):
$P=c \sqrt{Q o}$

where:

$$
\begin{aligned}
& P=\text { Wetted perimeter }[\mathrm{m}] \\
& c=\text { Coefficient }[\text { between } 4.71 \text { to } 4.81] \\
& Q_{0}=\text { Reference flow }\left[\mathrm{m}^{3} \cdot \mathrm{s}^{-1}\right]
\end{aligned}
$$

Equation for reference flow (Wilson and Ruffini, 1988):

$Q_{0}=Q_{b}+0.5\left(Q_{p^{-}} Q_{b}\right)$

where:

$$
\begin{aligned}
& Q_{b}=\text { minimum discharge }\left[\mathrm{m}^{3} \cdot \mathrm{s}^{-1}\right] \\
& Q_{p}=\text { peak discharge }\left[\mathrm{m}^{3} \cdot \mathrm{s}^{-1}\right]
\end{aligned}
$$

Slope $(S)$ of the channel reach were estimated from the topographic maps. The roughness coefficient $(n)$ for natural channel is 0.035 (Chow, 1988). In this study the roughness coefficient is calculated for different section at the upstream of the river Kulsi and was found approximately equal to 0.035 . The slope for each channel section of $15 \mathrm{KM}$ is obtained and substitute in Equation (22). The results obtained using KWM is shown in Figure 11

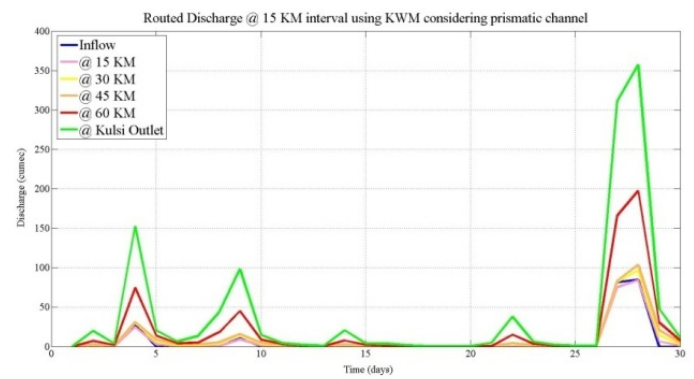

Figure 11. Routed Hydrograph at each channel section using Kinematic Wave Model for Kulsi River Watershed (Prismatic)

4.3 Variable Parameter Kinematic wave model (VPKWM) for Kulsi River Watershed considering as Non-Prismatic channel.

The Kinematic Wave Model (KWM) is modified by considering the channel is Non-Prismatic. Equation (21) is used to perform Variable Parameter Kinematic Wave Model (VPKWM). The solution of VPKWM model is obtained using finite difference implicit method in MATLAB software. The term ' $\alpha$ ' of Equation (21) is:

$\left.\alpha(i, j)=\left[n(P(i, j))^{\frac{2}{3}} / \sqrt{S_{0}}\right)\right]^{0.6}$

The wetted perimeter of natural waterways does not remain constant because of unsteady non-uniform flow and its irregular boundaries.

$P(i, j)=11.8 \sqrt{ } Q_{i+1}^{j} \quad($ Swamee.K.P. et.al, 2008)

The results obtained using VPKWM is shown in Figure 12. A comparison graph is plotted with the observed discharge data at the outlet of the Kulsi River Watershed, shown in Figure 13. 


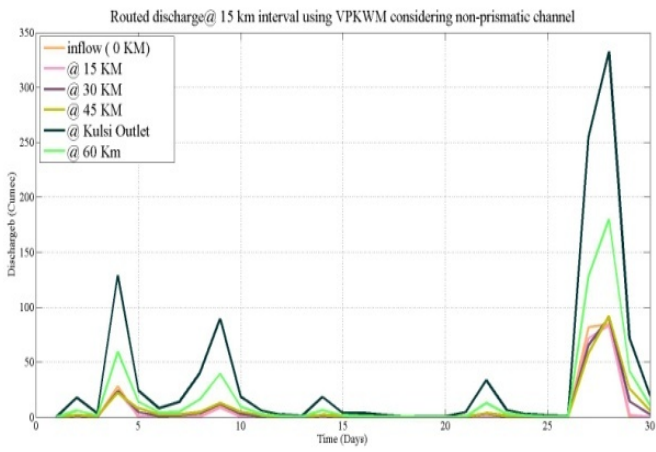

Figure 12. Routed Hydrograph at each channel section using Variable Parameter Kinematic Wave Model (VPKWM) for Kulsi River Watershed (Non-Prismatic)

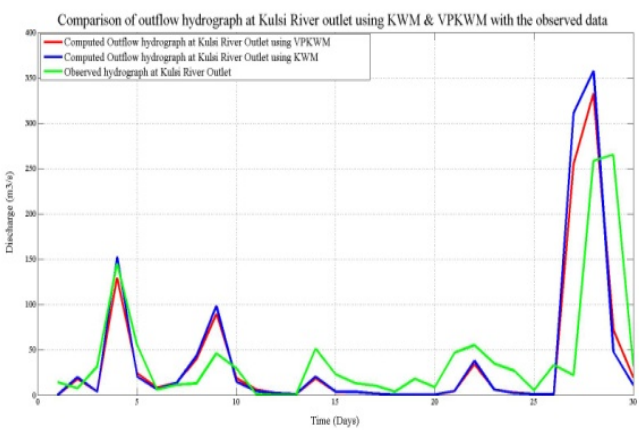

Figure 13. Comparison graph of predicted hydrograph using KWM and VPKWM at Kulsi Outlet with the Observed Data

\subsection{Performance of the Routing Models}

RMSE computes the magnitude of error in the computed hydrographs (O’Donnell, 1985; Schulze et al., 1995).

$R M S E=\sqrt{\frac{\sum_{\mathrm{i}=1}^{\mathrm{n}}(\mathrm{Q} c o m p-\mathrm{Qobs})^{2}}{\mathrm{n}}}, \mathrm{i}=1,2,3, \mathrm{n}$

As peak outflow is important in a single event model, a comparison of computed and observed peak flow rates, peak timing and volume were computed as shown in Equation (28, 29 and 30) (Green \& Stephenson, 1985).

$$
\begin{aligned}
& E_{\text {peak }}=\frac{Q p-c o m p-Q p-o b s}{Q p-o b s} \times 100 \\
& E_{\text {time }}=\frac{t p-c o m p-t p-o b s}{t p-o b s} \times 100 \\
& E_{\text {volume }}=\frac{\text { Vcomp }- \text { Vobs }}{\text { Vobs }} \times 100
\end{aligned}
$$

where:

$$
\begin{aligned}
& E_{\text {peak }}=\text { peak flow error }[\%] \\
& Q_{p \text {-comp }}=\text { computed peak flows }\left[\mathrm{m}^{3} \cdot \mathrm{s}-1\right] \\
& Q_{\text {-obs }}=\text { observed peak flows }\left[\mathrm{m}^{3} \cdot \mathrm{s}-1\right] \\
& E_{\text {time }}=\text { peak time error } \\
& t_{p \text {-comp }}=\text { time when } \mathrm{Q}_{\text {comp }} \text { occurs [days] } \\
& t_{p \text {-obs }}=\text { time when } \mathrm{Q}_{\text {obs }} \text { occurs [days] } \\
& E_{\text {volume }}=\text { peak volume error }[\%] \\
& V_{\text {comp }}=\text { computed total volume }\left[\mathrm{m}^{3}\right] \\
& V_{\text {obs }}=\text { observed total volume }\left[\mathrm{m}^{3}\right]
\end{aligned}
$$

The Root Mean Square Error (RMSE), Peak flow Error, Peak flow time Error and Total Volume Error of KWM are 71.57, $41.6 \%,-3.44 \%$ and $-6 \%$ respectively whereas for VPKWM the Root Mean Square Error (RMSE), Peak flow Error, Peak flow time Error and Volume Error are 60.37, $25.4 \%,-3.44 \%$ and $-12.4 \%$ respectively.

\section{DISCUSSION AND CONCLUSION}

In this study, both Prismatic Kinematic Wave Model (KWM) and Variable Parameter Kinematic Wave Model (VPKWM) are used to predict the outflow hydrograph at the outlet of the ungauged basin (Kulsi River Watershed). The lateral inflows are determined by using SCS-CN rainfall runoff model. Lateral inflows are considered in both the models. The performance of the models is obtained by considering four parameters (RMSE, Peak Flow, Peak Flow Time and Total Volume) with the field data at the outlet of the Kulsi River Watershed.

It has been observed that the error obtained by using Kinematic Wave Model (KWM) for peak discharge is higher than that obtained by using Variable Parameter Kinematic Wave Model (VPKWM). The peak flow time error is same for both the models. The Root Mean Square Error (RMSE) obtained by using KWM is higher than obtained by using VPKWM. VPKWM shows more accurate result as the model considered the variability of the wetted perimeter, Cross-Sectional area and slope of the natural channel. VPKWM is also able to consider the lateral inflow hydrograph due to which the flow parameters changes with space and time. Thus, one can predict outflow hydrograph at the outlet of the ungauged basin using VPKWM.

\section{References:}

Ambrose, R., \& Wool, T..,2017. WASP8 Stream TransportModel Theory and User's Guide.

Chapra, S. C.,1997. Surface Water-Quality Modeling: The McGraw-Hill Companies, Inc.

Chow, Ven T, David R. Maidment, and Larry W. Mays. 1988. Applied Hydrology. McGraw-Hill.

Engineer Manual 1994, Flood-Runoff Analysis. Department of the Army U.S. Army Corps of Engineers Washington DC, pp. 20314-1000,

Fread, D.L., 1981. Flood routing: a synopsis of past, present, and future capability. In: Singh, V.P. (Ed.), Rainfall-runoff Relationship, Proceedings of the International Symposium on Rainfall-runoff Modelling. Mississippi State University, U.S.A.

French, R.H., 1985. Open-Channel Hydraulics. McGraw-Hill Book Company, Inc., New York, 705.

Green Ira and Stephenson D,1985. Comparison of Urban Drainage Models for Use in South Africa. WRC Report No 115/6/86. Water Research Commission, Pretoria, RSA 
Nwaogazie, I. L.,1986. Comparative analysis of some explicitimplicit stream flow models. Adv. Water Resources, 10, 69-77. doi: 030917088702006909

O'Donnell, T., 1985. A direct three-parameter Muskingum procedure incorporating lateral inflow. Journal of Hydraulic Engineering, ASCE 30, 479e496

Punmia Bc and Pande Bbl., 1981. Irrigation and Water Power Engineering. Standard Publishers Distributors, Delhi, India.

Schulze Re.,1995. Hydrology and Agrohydrology: A Text to Accompany the ACRU 3.00 Agrohydrological Modelling System. WRC Report No TT 69/95. Water Research Commission, Pretoria, RSA.

Sivapalan, M., Takeuchi, K., Franks, S. W., Gupta, V. K., Karambiri, H., Lakshmi, V., Liang, X., McDonnell, J. J., Mendiondo, E. M., O'Connell, P. E., et al. 2003. IAHS decade on predictions in ungauged basins (PUB), 2003-2012: Shaping an exciting future for the hydrological sciences. Hydrological Sciences Journal, 48(6), 857-880. [doi:10.1623/hysj.48.6.857.51421]

Subramanya, K., 2008. Engineering Hydrology, 3rd ed., New Delhi: Tata Mc Graw -Hill.

Swamee. K.P, Sharma Nayan, Dwivedi Ambuj.,2008. Lacey regime equations for river Brahmaputra, Journal of Hydraulic Research,Vol. 46, No. 5 (2008), pp. 707-710 doi:10.3826/jhr.2008.3130

Wilson Bn And Ruffini Jr., 1988. Comparison of physicallybased Muskingum methods. Transactions of the ASAE. 31 (1) 91-97. 